\title{
Establishment of Hairy Root Cultures of Rhaponticum carthamoides (Willd.) Iljin for the Production of Biomass and Caffeic Acid Derivatives
}

\author{
Ewa Skała, ${ }^{1}$ Agnieszka Kicel, ${ }^{2}$ Monika A. Olszewska, ${ }^{2}$ \\ Anna K. Kiss, ${ }^{3}$ and Halina Wysokińska ${ }^{1}$ \\ ${ }^{1}$ Department of Biology and Pharmaceutical Botany, Medical University of Łódź, Muszyńskiego 1, 90-151 Łódź, Poland \\ ${ }^{2}$ Department of Pharmacognosy, Medical University of Łódź, Muszyńskiego 1, 90-151 Łódź, Poland \\ ${ }^{3}$ Department of Pharmacognosy and Molecular Basis of Phytotherapy, Medical University of Warsaw, \\ Banacha 1, 02-097 Warsaw, Poland \\ Correspondence should be addressed to Ewa Skała; ewa.skala@umed.lodz.pl
}

Received 27 December 2014; Accepted 5 February 2015

Academic Editor: Alberto Reis

Copyright () 2015 Ewa Skała et al. This is an open access article distributed under the Creative Commons Attribution License, which permits unrestricted use, distribution, and reproduction in any medium, provided the original work is properly cited.

The aim of the study was to obtain transformed roots of Rhaponticum carthamoides and evaluate their phytochemical profile. Hairy roots were induced from leaf explants by the transformation of Agrobacterium rhizogenes strains A4 and ATCC 15834. The best response (43\%) was achieved by infection with A4 strain. The effects of different liquid media (WPM, B5, SH) with full and half-strength concentrations of macro- and micronutrients on biomass accumulation of the best grown hairy root line (RC3) at two different lighting conditions (light or dark) were investigated. The highest biomass $\left(93 \mathrm{~g} \mathrm{~L}^{-1}\right.$ of the fresh weight after 35 days) was obtained in WPM medium under periodic light. UPLC-PDA-ESI-MS ${ }^{3}$ and HPLC-PDA analyses of $80 \%$ aqueous methanol extracts from the obtained hairy roots revealed the presence of eleven caffeoylquinic acids and their derivatives and five flavonoid glycosides. The production of caffeoylquinic acids and their derivatives was elevated in hairy roots grown in the light. Only lightgrown hairy roots demonstrated the capability for the biosynthesis of such flavonoid glycosides as quercetagetin, quercetin, luteolin, and patuletin hexosides. Chlorogenic acid, 3,5-di-O-caffeoylquinic acid and a tentatively identified tricaffeoylquinic acid derivative were detected as the major compounds present in the transformed roots.

\section{Introduction}

Rhaponticum carthamoides (Willd.) Iljin, a member of the Asteraceae family, is a perennial, herbaceous species naturally growing in the mountains of South Siberia, Middle Asia, and Mongolia. It is commonly known as "maral root" or Russian leuzea and has been used for centuries in traditional Siberian medicine as a stimulant, mostly in the case of overstrain and weakness after illness [1]. The root and rhizome extracts of $R$. carthamoides possess a wide range of biological activities, including adaptogenic, antioxidant, cardioprotective, immunomodulatory, antihyperlipidemic, antihyperglycemic, and antimicrobial effects [1]. These pharmacological properties are attributed to the presence of a variety of secondary metabolites including triterpenoids, polyacetylenes, sesquiterpene lactones, phenolic acids, flavonoids, and ecdysteroids with 20-hydroxyecdysone as the principal component [1].

The medicinal importance and endangered status of $R$. carthamoides, have resulted in its cultivation worldwide, including Central and Eastern Europe. However, 3-4 years are required to obtain plant roots with a satisfactory content of the pharmacologically active compounds by field cultivation. In addition, it is inefficient to harvest the roots from fieldgrown plants as these results in the loss of the mother plant. It would be desirable to develop an effective biotechnological method for the production of suitable plant material in a shorter time period, regardless of seasonal and climatic conditions. One approach could be the use of hairy root cultures transformed by Agrobacterium rhizogenes. This type 
TABLE 1: Induction of hairy roots of R. carthamoides derived from leaf explants by direct infection with Agrobacterium rhizogenes strains A4 and ATCC 15834.

\begin{tabular}{|c|c|c|c|c|c|}
\hline Bacterial strain & Site of infection & Medium & $\begin{array}{l}\% \text { of explants forming } \\
\text { roots }\end{array}$ & $\begin{array}{l}\text { Mean number of } \\
\text { roots/explants }\end{array}$ & Root length $(\mathrm{cm})$ \\
\hline \multirow{4}{*}{$\mathrm{A} 4$} & \multirow{2}{*}{ Petiole } & MS & $27.8^{\mathrm{a}}$ & $3.0 \pm 0.20^{\mathrm{a}}$ & $1.6 \pm 0.10^{\mathrm{a}}$ \\
\hline & & $\mathrm{MS}+\mathrm{AcS}$ & $37.3^{\mathrm{b}}$ & $3.1 \pm 0.14^{\mathrm{a}}$ & $1.7 \pm 0.08^{\mathrm{a}}$ \\
\hline & \multirow{2}{*}{ Lamina } & MS & $35.0^{\mathrm{ab}}$ & $2.1 \pm 0.12^{\mathrm{b}}$ & $1.5 \pm 0.10^{\mathrm{a}}$ \\
\hline & & $\mathrm{MS}+\mathrm{AcS}$ & $43.3^{\mathrm{b}}$ & $2.1 \pm 0.09^{b}$ & $1.6 \pm 0.08^{\mathrm{a}}$ \\
\hline \multirow{4}{*}{ ATCC 15834} & \multirow{2}{*}{ Petiole } & MS & $17.3^{\mathrm{cd}}$ & $1.7 \pm 0.22^{\mathrm{bc}}$ & $1.2 \pm 0.13^{\mathrm{a}}$ \\
\hline & & $\mathrm{MS}+\mathrm{AcS}$ & $22.7^{\mathrm{d}}$ & $1.3 \pm 0.11^{\mathrm{c}}$ & $1.2 \pm 0.11^{\mathrm{a}}$ \\
\hline & \multirow{2}{*}{ Lamina } & MS & $13.3^{\mathrm{c}}$ & $1.5 \pm 0.19^{\mathrm{c}}$ & $1.3 \pm 0.11^{\mathrm{a}}$ \\
\hline & & $\mathrm{MS}+\mathrm{AcS}$ & $18.3^{\mathrm{cd}}$ & $1.3 \pm 0.12^{\mathrm{c}}$ & $1.6 \pm 0.14^{\mathrm{a}}$ \\
\hline
\end{tabular}

Explants were infected with a needle dipped in the bacterial culture and placed on hormone-free MS agar (0.7\%) medium without (MS) or with $200 \mu \mathrm{M}$ acetosyringone (MS + AcS). Observations were recorded after 5 weeks. Each treatment involved 25-35 explants. The experiments were repeated three times. Values are given as the mean \pm SE (standard error). The experiment means followed by the same superscript letter within the column are not significantly different at the level of $P \geq 0.05$ (the Mann-Whitney $U$ test).

of in vitro culture has gained considerable attention because of their fast growth in media without growth regulators, their genetic and biochemical stability and their ability to biosynthesise selected secondary metabolites at levels comparable to, or even higher than, those found in roots of intact plants [2, 3]. A previous work [4] reports that transformed root cultures of $R$. carthamoides were found to be ineffective for ecdysone production, but no information is available regarding polyphenol accumulation and no optimization data is given for biomass production by the culture.

The aim of this study was the establishment of hairy roots of $R$. carthamoides and the phytochemical profiling of their polyphenolic constituents. Two A. rhizogenes strains (A4 and ATCC 15834) and leaf explants were used for hairy root induction. The effect of different liquid nutrient media (WPM, B5, SH and 1/2 WPM, 1/2 B5, 1/2 SH) and culture conditions (light or dark) on hairy root growth, in terms of fresh and dry biomass accumulation, were also investigated. The incorporation of T-DNA genes into the plant genome was demonstrated by PCR analysis.

Furthermore, the hairy root cultures exhibiting the highest biomass productivity and roots of the soil-cultivated plants of $R$. carthamoides were characterized to their main phytochemical markers, including caffeoylquinic acids, flavonoid glycosides, and 20-hydroxyecdysone. The comprehensive qualitative and quantitative phytochemical profiling of the plant samples was performed by UPLC-PDA-ESI-MS ${ }^{3}$ and HPLC-PDA methods.

\section{Material and Methods}

2.1. Plant Material and Bacterial Strains. The leaves of fourweek-old in vitro shoots of $R$. carthamoides (derived from seeds obtained from the Medicinal Plant Garden of the Department of Pharmacognosy, Medical University of Łódź, Poland) cultured on Murashige and Skoog (MS) agar (0.7\%) medium [5] containing $0.1 \mathrm{mg} \mathrm{L}^{-1}$ indole-3-aceticacid and $0.2 \mathrm{mg} \mathrm{L}^{-1}$ benzyladenine were used as a explants for
Agrobacterium rhizogenes-mediated transformation. Botanical identity of plants was confirmed by E. Skała according to Flora of China (http://www.efloras.org/). The voucher specimen was deposited at the Department of Biology and Pharmaceutical Botany, Medical University of Łódź (Poland).

Two agropine-type strains of Agrobacterium rhizogenes (A4 and ATCC 15834) were used for hairy root induction. The bacteria were grown for $48 \mathrm{~h}$ on YEB solid (1.5\%) medium [6], at $26^{\circ} \mathrm{C}$ in the dark.

2.2. Induction and Establishment of Hairy Root Culture. The leaf explants were wounded with a sterile needle immersed in the bacterial culture. Inoculation was carried out in the middle part of the petiole or at the basal part of the leaf lamina. Control explants were wounded identically with sterile needle without bacteria. Infected and control explants were placed on hormone-free MS agar $(0.7 \%)$ medium with or without acetosyringone (AcS) $(200 \mu \mathrm{M})$ and incubated in the dark for 5 weeks. The experiment was repeated three times; 2535 explants were used for each treatment: type of bacterial strain/site of infection/medium with or without AcS.

Five weeks after initial inoculation, the transformation frequency (the percentage of explants forming roots after infection with $A$. rhizogenes with respect to total number of infected explants), the number of roots per responding explant, and the root length were determined (Table 1).

2.3. Liquid Culture of Hairy Roots. Adventitious roots $(1-2 \mathrm{~cm}$ long) (Figure 1(a)) were excised from explants and transferred individually into $100 \mathrm{~mL}$ Erlenmeyer flasks containing $20 \mathrm{~mL}$ half-strength Gamborg (1/2 B5) liquid medium [7] without growth regulators and supplemented with $500 \mathrm{mg} \mathrm{L}^{-1}$ ampicillin for the elimination of the bacteria. The cultures were maintained in the dark, on a rotary shaker at $80 \mathrm{rpm}$. After several subcultures of 7 days each, the concentration of ampicillin was reduced to $300 \mathrm{mg} \mathrm{L}^{-1}$. After four successive subcultures, the antibiotic was eliminated from the medium and eight axenic root lines were obtained (RC1-RC8). Among them, line RC3, showed the fastest 


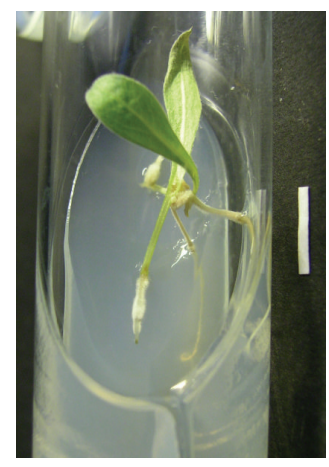

(a)

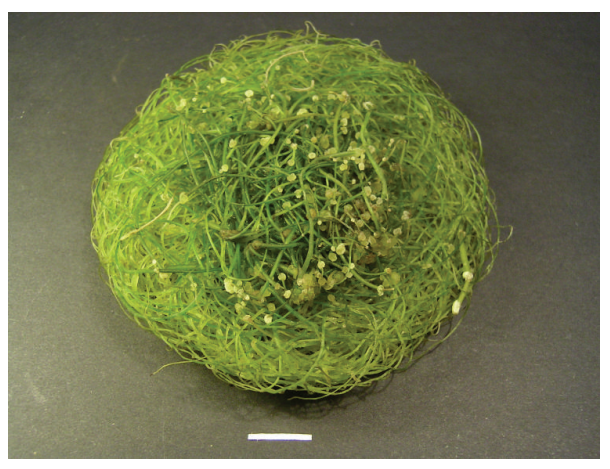

(b)

Figure 1: The hairy roots of $R$. carthamoides. (a) Induction of the hairy roots of the leaves after 4 weeks on MS agar (0.7\%) medium. (b) Light-grown hairy roots cultured in $300 \mathrm{~mL}$ Erlenmeyer flasks containing $80 \mathrm{~mL}$ phytohormone-free WPM liquid medium after 35 days $($ bar $=1 \mathrm{~cm})$.

growth and produced more lateral roots than the other seven lines. Therefore, this line was chosen for further experiments.

2.4. Culture of R. carthamoides Hairy Roots in Different Media. Six different liquid media were tested for their effect on root biomass production: Schenk and Hildebrandt (SH) [8], Woody Plant (WPM) [9], and Gamborg (B5) with full and half-strength macro- and microsalt concentration $(1 / 2 \mathrm{SH}$, $1 / 2$ WPM, $1 / 2$ B5). The media contained $3 \%$ sucrose. The experiments were carried out in $300 \mathrm{~mL}$ Erlenmeyer flasks containing $80 \mathrm{~mL}$ of the liquid medium. The flasks were maintained on a rotary shaker at $80 \mathrm{rpm}$, in the darkness or under a $16 / 8 \mathrm{~h}$ light/dark photoperiod; PPFD of $40 \mu \mathrm{mol} \mathrm{m}^{-2} \mathrm{~s}^{-1}$ using cool-white fluorescent lamp. Subcultures were carried out every 5 weeks by transferring $0.4-0.6 \mathrm{~g}$ of fresh root biomass into fresh medium. Measurement of biomass accumulation was calculated as both fresh (FW) and dry (DW) weights after 5 weeks of culture. The morphology of hairy roots (colour, thickness, and intensity of branches) was also evaluated. Three flasks from three successive subcultures (15-17 passages) were used for each medium type and culture conditions (darkness/photoperiod). The thickness of the hairy roots was estimated with the Motic Images Plus 2.0 ML computer application (2006) connected to a light microscope (Delta Optical Genetic Pro) (Poland). The hairy roots were found to be stable in terms of increase in root biomass and their morphology.

2.5. DNA Isolation and PCR Analysis. Genomic DNA was extracted from fresh hairy roots (RC3 line) and nontransformed shoots of $R$. carthamoides using NucleoSpin Plant II Kit (Macherey-Nagel, Germany). The plant materials $(200 \mathrm{mg})$ were powdered in liquid nitrogen. Each DNA sample was used as a template for PCR analysis to determine the presence of the rolA, rolB, rolC, rolD, auxl, and $a u x 2$ genes in the T-DNA. In order to confirm that the hairy roots were correctly transformed, PCR was performed using virG gene. The sequence of primers used to amplify the genes is given in Table 2. The Ri plasmid was isolated from $24 \mathrm{~h}$ cultures
TABLE 2: Specific pairs of primers used for PCR analysis of transformed roots of $R$. carthamoides.

\begin{tabular}{|c|c|c|}
\hline Gene & Primer sequences & $\begin{array}{c}\text { Amplified } \\
\text { fragments } \\
\text { (bp) }\end{array}$ \\
\hline rolA & $\begin{array}{l}5^{\prime} \text { CTA AGG TCA AGA AGA AGA AGG } 3^{\prime} \\
5^{\prime} \text { AGA AGT TAT AGC CAG AGG AGT } 3^{\prime}\end{array}$ & 107 \\
\hline rolB & $\begin{array}{l}5^{\prime} \text { GCT CTT GCA GTG CTA GAT TT } 3^{\prime} \\
5^{\prime} \text { GAA GGT GCA AGC TAC CTC TC } 3^{\prime}\end{array}$ & 386 \\
\hline rolC & $\begin{array}{l}5^{\prime} \text { CTC CTG ACA TCA AAC TCG TC } 3^{\prime} \\
5^{\prime} \text { TGC TTC GAG TTA TGG GTA CA } 3^{\prime}\end{array}$ & 582 \\
\hline rolD & $\begin{array}{l}5^{\prime} \text { GAT GAT TTT CGT TTT ATC AAG 3' } \\
5^{\prime} \text { GAA GGA CAG AGG ATA CTT AAA C } 3^{\prime}\end{array}$ & 204 \\
\hline $\operatorname{auxl}$ & $\begin{array}{l}5^{\prime} \text { ATC TTA GTC ACT TCA TAG CAG TT } 3^{\prime} \\
5^{\prime} \text { CTT TTT GAG ATA GAA GAA CAA G } 3^{\prime}\end{array}$ & 500 \\
\hline $\operatorname{aux} 2$ & $\begin{array}{l}5^{\prime} \text { ATA TCT GCT TCA ACA AAA GTA AC } 3^{\prime} \\
5^{\prime} \text { TGA GTT AAT CGA AAC GAT AAT A } 3^{\prime}\end{array}$ & 774 \\
\hline $\operatorname{vir} \mathrm{G}$ & $\begin{array}{l}5^{\prime} \text { AGT TCA ATC GTG TAC TTT CCT } 3^{\prime} \\
5^{\prime} \text { CTG ATA TTC AGT GTC CAG TCT } 3^{\prime}\end{array}$ & 319 \\
\hline
\end{tabular}

from Agrobacterium rhizogenes, strain A4 $\left(\mathrm{OD}_{600}=0.5\right)$ using Plasmid Mini AX Kit (A\&A Biotechnology, Poland).

PCR amplification was performed in a $25 \mu \mathrm{L}$ volume containing $5 \mu \mathrm{L}$ DNA solution, $5 \mu \mathrm{L}$ of each primer (forward and reverse), $2.5 \mu \mathrm{L} 10 \mathrm{x}$ TaqNova reaction buffer (Blirt, Poland), $1.25 \mu \mathrm{L} \mathrm{MgCl}_{2}$ (2.5 mM), $2 \mu \mathrm{L}$ dNTP mix (0.2 mM) (Blirt, Poland), and $0.6 \mu \mathrm{L} 2 \mathrm{U} / \mu \mathrm{L}$ TaqNova DNA polymerase (Blirt, Poland). The PCR programme comprised 36 cycles in which first denaturation was carried out at $95^{\circ} \mathrm{C}$ for $2.30 \mathrm{~min}$, segment denaturation at $95^{\circ} \mathrm{C}$ for $0.30 \mathrm{~min}$, annealing at $55^{\circ} \mathrm{C}$ for $0.30 \mathrm{~min}$, extension at $72^{\circ} \mathrm{C}$ for $1.10 \mathrm{~min}$, and final extension for $3 \mathrm{~min}$ at $72^{\circ} \mathrm{C}$. The PCR products were analyzed with a 100 bp DNA ladder on 1.2\% agarose gel (Bioline, UK) for $1 \mathrm{~h}$ at a constant voltage of $90 \mathrm{~V}$ in TBE buffer. The gel was stained with ethidium bromide, visualized under UV light, and photographed using DNR Bio-Imaging System MiniBIS Pro (Israel). 


\subsection{Phytochemical Analysis}

2.6.1. Chemicals and Standards. The standards of HPLCgrade purity $(\geq 96 \%)$ such as chlorogenic acid (5-O-caffeoylquinic acid, CHA), cynarin (1,3-di-O-caffeoylquinic acid, $\mathrm{CA}$ ), and isoquercitrin (quercetin 3-O- $\beta$-D-glucopyranoside, IQ) were purchased from Fluka (Germany) and 20-hydroxyecdysone (EC) from Sigma-Aldrich (Germany/USA). HPLC grade solvents, acetonitrile, orthophosphoric acid, and redistilled water were obtained from $\mathrm{POCH}$ (Poland) and Merck (Germany).

2.6.2. Extraction Procedure. An accurately weighed sample of lyophilized and powdered plant material was first extracted with $n$-hexane. The samples were $600 \mathrm{mg}$ for the 35-dayold hairy roots cultured in WPM medium in the light (HRL) or in the dark (HR-D) and $300 \mathrm{mg}$ for the roots of soilgrown 3-year-old plants (SR). After filtration, the $n$-hexane extract was discarded. The defatted sample was sonicated for $15 \mathrm{~min}$ with $80 \%(\mathrm{v} / \mathrm{v})$ aqueous methanol $(25 \mathrm{~mL})$ at $35^{\circ} \mathrm{C}$ using an ultrasonic bath and then twice with $10 \mathrm{~mL}$ of the same solvent for $15 \mathrm{~min}$. The combined extracts were diluted with methanol to $50 \mathrm{~mL}$, filtered through a PTFE syringe filter (25 mm, $0.2 \mu \mathrm{m}$, AlChem, Czech Republic) and the filtrate was directly injected into the HPLC or UPLC system.

2.6.3. Qualitative UPLC-PDA-ESI-MS ${ }^{3}$ Analysis. The UPLCPDA-ESI-MS ${ }^{3}$ analysis was performed using an UPLC-3000 RS system (Dionex, Germany) equipped with a dual lowpressure gradient pump, an autosampler, a column compartment, a diode array detector, and an AmaZon SL ion trap mass spectrometer with an ESI interface (Bruker Daltonik, Germany). The samples were separated on a Kinetex XB-C18 column $(1.7 \mu \mathrm{m}, 150 \times 2.1 \mathrm{~mm}$ i.d., Phenomenex, USA). The mobile phase consisted of solvent A $(0.1 \%$ aqueous solution of formic acid, v/v) and solvent B (acetonitrile with $0.1 \%$ formic acid, v/v) with an elution profile as follows: $0-45 \mathrm{~min}$ 6-26\% B (v/v), 45-55 min 26-95\% B, 55-63 min 95\% B, and $63-70 \mathrm{~min} 95-6 \% \mathrm{~B}$. The flow rate was $0.3 \mathrm{~mL} \mathrm{~min}^{-1}$, the column temperature was maintained at $25^{\circ} \mathrm{C}$. The UVVis spectra were recorded over the range $200-600 \mathrm{~nm}$, and chromatograms were acquired at 245,325 , and $350 \mathrm{~nm}$. The LC eluate was introduced directly into the ESI interface without splitting. The nebulizer pressure was 40 psi; dry gas flow $9 \mathrm{~L} \mathrm{~min}^{-1}$; dry temperature $300^{\circ} \mathrm{C}$; and capillary voltage $4.5 \mathrm{kV}$. The analysis was carried out using a scan from $\mathrm{m} / \mathrm{z}$ 200 to 2200 . The compounds were analyzed in a negative ion mode.

2.6.4. Quantitative HPLC-PDA Analysis. The HPLC-PDA analysis was performed on the Waters 600E Multisolvent Delivery System (Waters, USA) with a PDA detector (Waters 2998) working in the range of $220-450 \mathrm{~nm}$, a model 7725 sample injection value (Rheodyne, CA, USA), a $5 \mu \mathrm{L}$ injection loop, and a LC workstation equipped with Waters Empower 2 software for data collection and acquisition. The analytical column was a C18 Ascentis Express $(2.7 \mu \mathrm{m}, 75 \mathrm{~mm} \times 4.6 \mathrm{~mm}$ i.d.; Supelco, PA, USA), guarded by a C18 Ascentis C18
Supelguard column $(3 \mu \mathrm{m}, 20 \mathrm{~mm} \times 4 \mathrm{~mm}$ i.d.; Supelco $)$ The mobile phase consisted of solvent A ( $0.5 \%$ aqueous solution of orthophosphoric acid, w/v) and solvent B (acetonitrile) with an elution profile as follows: $0-1 \mathrm{~min} 5 \% \mathrm{~B}(\mathrm{v} / \mathrm{v}), 1-$ 16 min $5-30 \%$ B, $16-17$ min $30-50 \%, 17-19$ min $50 \%$ B, 19$20 \mathrm{~min} 50-5 \% \mathrm{~B}$, and $20-25 \mathrm{~min} 5 \% \mathrm{~B}$ (equilibration). The flow rate was $1.4 \mathrm{~mL} \mathrm{~min}^{-1}$ and the column temperature was maintained at $30^{\circ} \mathrm{C}$. The phenolic compounds were identified and classified into three groups based on their UV-Vis spectra, retention times, and the qualitative results obtained from UPLC-PDA-ESI-MS ${ }^{3}$ (the accurate mass and the MS fragmentation patterns). The detection wavelength was set at $245 \mathrm{~nm}$ for 20-hydroxyecdysone, $325 \mathrm{~nm}$ for caffeic acid derivatives including caffeoylquinic acids, and $350 \mathrm{~nm}$ for the flavonoid glycosides. Four external standards were used for calibration including chlorogenic acid (CHA), cynarin (CA), 20-hydroxyecdysone (EC), and isoquercitrin (IQ). The calibration equations were constructed using seven concentration levels of each analyte within the range of approximately $2.4-240 \mu \mathrm{g} \mathrm{mL}^{-1}$ for CHA, $1.0-100 \mu \mathrm{g} \mathrm{mL}^{-1}$ for CA, 1.0-107 $\mu \mathrm{g} \mathrm{mL}^{-1}$ for EC, and $1.0-103 \mu \mathrm{g} \mathrm{mL} \mathrm{mL}^{-1}$ for IQ. The tentatively identified peaks were quantified as equivalents of the following standards: chlorogenic acid isomers as CHA, dicaffeoylquinic acid isomers, tricaffeoylquinic acid and its derivative as CA, 20-hydroxyecdysone as EC, and the flavonoid monoglycosides as IQ.

2.7. Statistical Analysis. The statistics (calculation of RSD and SE, one-way analysis of variance, significance tests, and linearity studies) were performed using the software Statistica 10.0PL for Windows (StatSoft Inc., Poland).

\section{Results and Discussion}

3.1. Induction of Hairy Roots. The first adventitious roots were visible 2-3 weeks after inoculation. No roots were observed in noninfected control explants. The highest frequency of hairy root induction was achieved on explants infected with strain A4 and cultured on MS medium supplemented with AcS. It was $43.3 \%$ when leaf explants were wounded at the lamina base and $37.3 \%$ after infection at the middle part of the petiole. The differences were not statistically significant $(P \geq 0.05)$ (Table 1). It has been well documented that bacterial strains differ in their virulence and the choice of the appropriate strain is an important factor for successful transformation $[10,11]$. After infection with strain ATCC 15834, 18.3\% of lamina and $22.7 \%$ of petiole explants responded by producing roots after 5 weeks of culture on MS medium containing AcS $(200 \mu \mathrm{M})$ (Table 1$)$. The site of infection also did not have any significant effect on frequency of hairy root induction.

Acetosyringone (AcS) has been reported to induce the expression of vir genes and thus affect Agrobacteriummediated transformation [12]. Therefore, it was added to $R$. carthamoides root induction medium at the concentration of $200 \mu \mathrm{M}$, a concentration which was found to have a positive effect on the transformation frequency of Picrorhiza kurroa [13]. It was found that the addition of $200 \mu \mathrm{M} \mathrm{AcS}$ to MS medium for R. carthamoides root initiation increased 


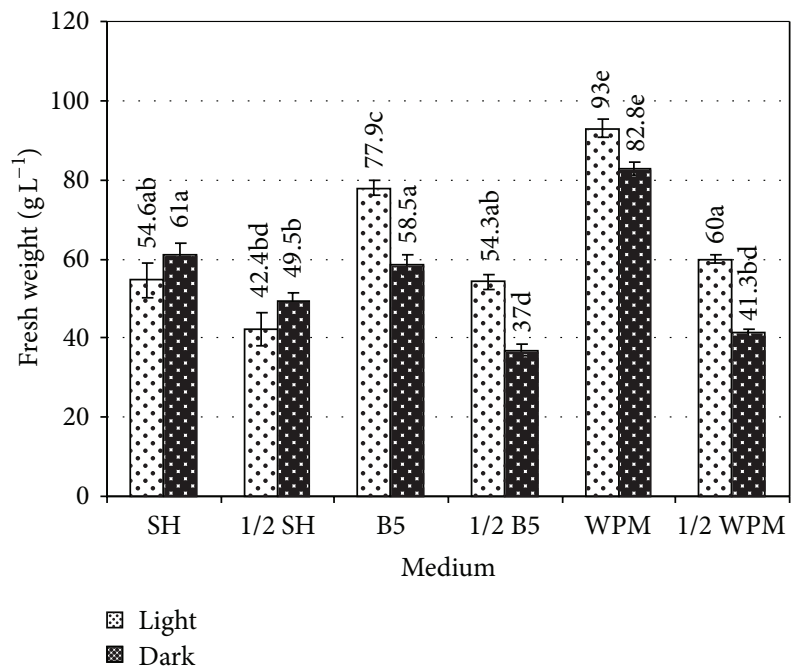

(a)

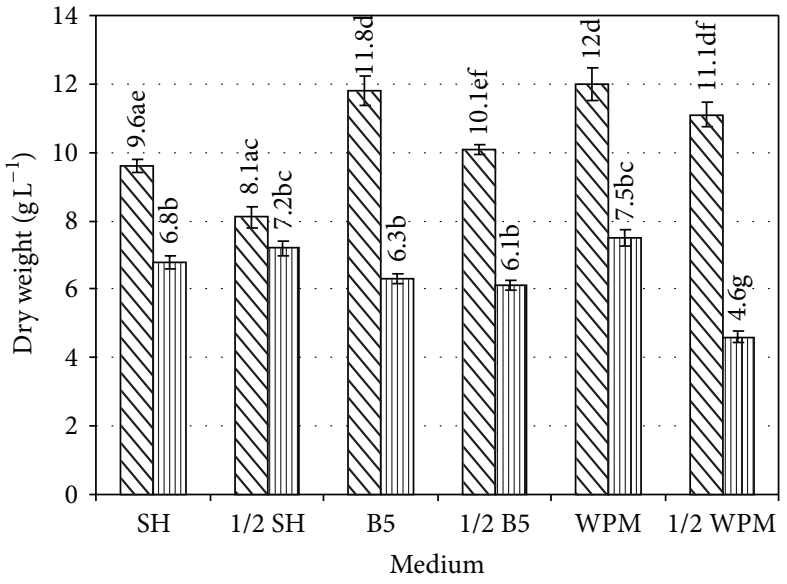

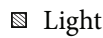

$\square$ Dark

FIGURE 2: Comparative growth of $R$. carthamoides transformed roots after 35 days in liquid medium in the light (photoperiod: $16 \mathrm{~h}$ of light: $40 \mu \mathrm{mol} \mathrm{m}^{-2} \mathrm{~s}^{-1}$ ) and in the dark. (a) Fresh weight (g) of harvested biomass per liter. (b) Dry weight (g) of harvested biomass per liter. The values are the mean \pm SE of three successive subcultures (15-17). Means followed by the same letter at the columns (individually to fresh and dry weight) are not significantly different at the level of $P \geq 0.05$ (the Mann-Whitney $U$ test).

the number of explants producing roots, although the effect was not statistically significant at $P=0.05$ (Table 1 ). The relatively low differences in root formation between treatments given with and without AcS suggest that this compound is not a key factor in the transformation of $R$. carthamoides, which may be due to the high level of phenolic compounds present in the leaf explants.

3.2. Growth of Hairy Roots in Different Liquid Media. The hairy roots (RC3 line) grown in full strength media possessed greater biomass than roots cultured in half-strength media (Figures 2(a) and 2(b)). This was similar to hairy root cultures of Levisticum officinale grown in B5 medium, which showed a greater increase in biomass $\left(350 \mathrm{~g} \mathrm{~L}^{-1} \mathrm{FW}\right.$ and $10 \mathrm{~g} \mathrm{~L}^{-1}$ DW) than roots grown in $1 / 2 \mathrm{~B} 5$ medium $\left(200 \mathrm{gL}^{-1} \mathrm{FW}\right.$ and $7 \mathrm{~g} \mathrm{~L}^{-1} \mathrm{DW}$ ) [14]. In the present study, the highest accumulation of hairy root biomass was achieved in WPM medium with a full concentration of nutrients. After 35 days, the fresh weight of hairy roots was $93 \mathrm{~g} \mathrm{~L}^{-1}$ grown in photoperiod and $82.8 \mathrm{~g} \mathrm{~L}^{-1}$ for roots cultured in the dark (Figure 2(a)). The values for dry weights were $12.0 \mathrm{~g} \mathrm{~L}^{-1}$ and $7.5 \mathrm{~g} \mathrm{~L}^{-1}$, respectively (Figure 2(b)). The roots were thin with an average root diameter of $0.5 \mathrm{~mm}$ and had long and numerous branches (Figure 1(b)). The WPM medium was also the best for the growth of transformed roots of other plant species like as Trigonella foenum-graecum [15] or Dracocephalum moldavica [16]. Of the tested media, SH, B5, and WPM with half-strength macro- and microsalt concentration were found to induce the lowest level of $R$. carthamoides root biomass in terms of both fresh and dry weights (Figures 2(a) and 2(b)). The transformed roots maintained in SH and $\mathrm{B} 5$ media with full and half-strength content of macro- and micronutrients were thick with an average root diameter of $0.9-1.5 \mathrm{~mm}$ and had short and small branches. Generally, exposure to light increased the growth of hairy roots of $R$. carthamoides, except for the roots cultured in $\mathrm{SH}$ and $1 / 2 \mathrm{SH}$ media. In these media fresh weights of the roots grown under photoperiod were lower than those achieved under darkness. However, the differences were not statistically significant at $P=0.05$. The hairy roots were found to be stable in terms of increase in root biomass and their morphology. The physical culture conditions affected also the morphology of $R$. carthamoides hairy roots; that is, roots cultured in the photoperiod were green (Figure 1(b)). Greening was absent in the dark-grown roots which were beige. The previous report results showed that exposure of hairy root cultures to light can induce greening due to enhanced chlorophyll biosynthesis $[17,18]$.

3.3. PCR Analysis. The genetic transformation of the $R$. carthamoides hairy roots was confirmed by PCR. Using specific PCR primers four amplified bands of expected size $107 \mathrm{bp}, 386 \mathrm{bp}, 582 \mathrm{bp}$, and $500 \mathrm{bp}$ corresponding to the rolA, rolB, rolC, and auxl genes, respectively, appeared in the hairy root line RC3 (Figure 3, lanes 8, 9, 10, and 13, resp.) but not in the nontransformed shoots used as a negative control. PCR analysis was carried out using primers specific to $\operatorname{vir} \mathrm{G}$ to confirm that hairy roots were not contaminated with $A$. rhizogenes (Figure 3, lane 12).

The results of the PCR analysis revealed the insertion of both $\mathrm{T}_{\mathrm{L}}$-DNA (the presence of $\mathrm{A}, \mathrm{B}, \mathrm{C}$ rol gene fragments) and $T_{R}-D N A$ (the presence of the auxl gene fragment) into the genome of $R$. carthamoides hairy roots.

3.4. Identification of Polyphenols and 20-Hydroxyecdysone in Hairy Roots and Roots of Soil-Grown Plants by UPLC-PDA$E S I-M S^{3}$. The UPLC-PDA-ESI-MS ${ }^{3}$ studies of $80 \%$ aqueous 

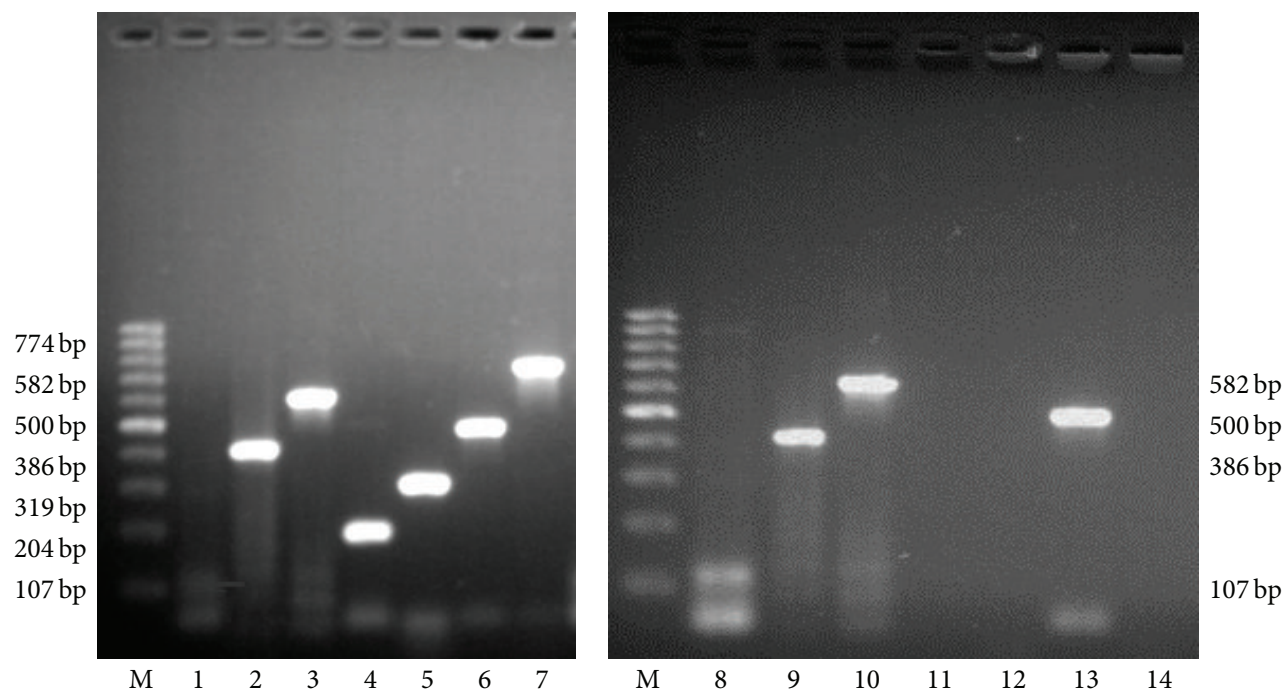

FIGURE 3: PCR analysis of genomic DNA isolated from Rhaponticum carthamoides hairy roots. Lanes: M: molecular weight marker (100 bp DNA ladder); 1-7 positive control (plasmid DNA from A. rhizogenes strain A4), DNA showing rolA (107 bp), rolB (386 bp), rolC (582 bp), rolD (204 bp), virG (319 bp), aux1 (500 bp), and aux2 (774 bp) genes; 8-14 genomic DNA of hairy roots (RC3 line).

methanol extracts of HR-L and HR-D hairy roots cultured in liquid medium WPM and roots of soil-grown 3-year-old plants (SR) of R. carthamoides resulted in full or partial identification of 17 compounds comprising caffeoylquinic acids and their derivatives, 20-hydroxyecdysone and flavonoids (Table 3). The detected compounds were identified by comparing their retention times, UV-Vis spectra, and fragmentation patterns in MS spectra with those of the reference compounds and the literature data [19-22].

The UPLC-PDA study showed that the caffeoylquinic acids and their derivatives constitute the major phenolic class occurring in both the hairy roots and the roots of soil-grown plants. These compounds (peaks 1-4 and 11-15), based on their parent ions in the negative mode $\left([\mathrm{M}-\mathrm{H}]^{-}\right.$at $m / z 353$, 515, and 677), were classified into three groups: mono-, di-, and tricaffeoyl esters of quinic acid. The monocaffeoylquinic acids (compounds 1-3) were located on the chromatograms by their parent deprotonated ions $[\mathrm{M}-\mathrm{H}]^{-}$at $\mathrm{m} / z 353$. Their preliminary identification was facilitated by analysis of structure-diagnostic hierarchical keys proposed by Clifford et al. [19]. Compounds $\mathbf{1}$ and $\mathbf{2}$, exhibiting the $\mathrm{MS}^{2}$ base ions at $m / z 191$ and the secondary ions at $m / z 179$ of the intensity of $43 \%$ and $4 \%$, respectively, were identified as NCHA (neochlorogenic acid, 3-O-caffeoylquinic acid) and CHA (chlorogenic acid, 5-O-caffeoylquinic acid), respectively. The third isomer (compound 3 ), due to its $\mathrm{MS}^{2}$ base ion observed at $m / z 173$, was assigned as CCHA (cryptochlorogenic acid, 4$O$-caffeoylquinic acid). Finally, the unequivocal identification of compounds 1-3 was confirmed by comparison of their retention time and MS data with the commercially available standard of CHA as well as with the qualitative standards of NCHA and CCHA prepared in our laboratory according to Clifford et al. [23].

The further five compounds (4 and 11-14) (Table 3), eluting after chlorogenic acid, were classified as dicaffeoylquinic acids, all of which exhibited the UV-Vis absorption maxima at 325 or $328 \mathrm{~nm}$ and whose deprotonated molecular ions were found at $m / z 515$. In the MS ${ }^{2}$ spectra, these compounds gave base peaks at $m / z 353$ ([M-H-caffeoyl $]^{-}$) and the secondary ions at $m / z 335$ or 191 with varying intensities $(10-30 \%$ of the base peak). Additionally, at the $\mathrm{MS}^{3}$ level, the base peak at $\mathrm{m} / \mathrm{z}$ 173 was characteristic of the isomers with a caffeoyl moiety substituted at position C-4 of quinic acid, whereas other substitutions gave base peaks at $m / z 191$. A comparison of the elution order and the fragmentation patterns of the product ions described above to those reported in the literature for dicaffeoylquinic acids [21, 24] suggests that the detected isomers 4 and 11-14 were 1,3-; 3,4-; 3,5-; 1,5-; and 4,5-Odicaffeoylquinic acids, respectively. Finally, compound 4 was compared with the commercial standard of cynarin (1,3-di$O$-caffeoylquinic acid).

A search for tricaffeoylquinic acids with the deprotonated molecular ion at $\mathrm{m} / \mathrm{z} 677$ and typical UV-Vis absorption maxima at $325 \mathrm{~nm}$ resulted in the identification of one chromatographic peak. On the basis of its $\mathrm{MS}^{2}$ base peak at $\mathrm{m} / \mathrm{z} 497$ and the secondary ion at $\mathrm{m} / \mathrm{z} 515$ (20\% of base peak intensity), which yielded an $\mathrm{MS}^{3}$ base peak at $m / z 353$, the compound 15 was identified as 1,4,5-tri-O-caffeoylquinic acid, according to the literature data $[20,21]$.

As shown in Table 3, there are two further compounds with UV-Vis spectra typical of caffeic acid derivatives with absorption maxima at $327-329 \mathrm{~nm}$. These compounds, eluting after compound 15 , both with the deprotonated molecular ions at $m / z$ 793, produced similar $\mathrm{MS}^{2}$ and $\mathrm{MS}^{3}$ base peaks at $m / z 631$ ([M-H-caffeoyl $]^{-}$) and 469 ([M-caffeoylcaffeoyl-H $\left.]^{-}\right)$, respectively. In the $\mathrm{MS}^{3}$ spectra, neutral losses of 116 mass units were also observed forming the fragment ions at $\mathrm{m} / \mathrm{z} 353$ characteristic of monocaffeoylquinic acid. Based on these results, the detected compounds $\mathbf{1 6}$ and 17 might be only tentatively identified as two isomers of 
TABLE 3: UPLC-PDA-ESI-MS ${ }^{3}$ data of detected and identified polyphenols in hairy roots and in the roots of soil-grown plant extracts of $R$. carthamoides.

\begin{tabular}{|c|c|c|c|c|c|c|}
\hline Number & Compound & $\begin{array}{c}t_{R} \\
(\mathrm{~min}) \\
\end{array}$ & $\mathrm{UV}(\mathrm{nm})$ & $\begin{array}{c}{[\mathrm{M}-\mathrm{H}]^{-}} \\
m / z\end{array}$ & $\mathrm{MS}^{2}$ ions & $\mathrm{MS}^{3}$ ions \\
\hline 1 & 3-O-Caffeoylquinic acid & 6.6 & $294 \mathrm{sh}, 325$ & 353 & $191^{\mathrm{b}}, 179,135$ & - \\
\hline 2 & 5-O-Caffeoylquinic acid ${ }^{\mathrm{a}}$ & 10.9 & 294sh, 325 & 353 & $191^{\mathrm{b}}, 179,135$ & $171^{\mathrm{b}}, 127,85^{\mathrm{b}}$ \\
\hline 3 & 4-O-Caffeoylquinic acid & 12.9 & $294 \mathrm{sh}, 325$ & 353 & $191,179,173^{\mathrm{b}}$ & - \\
\hline 4 & 1,3-Di-O-caffeoylquinic acid ${ }^{\mathrm{a}}$ & 19.4 & $294 \mathrm{sh}, 328$ & 515 & $353^{\mathbf{b}}, 335,191,179$ & $191^{\mathrm{b}}, 179,135$ \\
\hline 5 & Quercetagetin hexoside & 22.4 & 259,356 & 479 & $385,317^{\mathrm{b}}$ & - \\
\hline 6 & Quercetin hexoside & 25.1 & 253,365 & 463 & $301^{\mathrm{b}}$ & $179^{\mathrm{b}}, 151$ \\
\hline 7 & Quercetin hexoside & 26.5 & 254,368 & 463 & $301^{\mathrm{b}}$ & $179^{\mathrm{b}}, 151$ \\
\hline 8 & 20-Hydroxyecdysone $\mathrm{a}^{\mathrm{a}}$ & 27.4 & 247 & $479,525^{\mathrm{c}}$ & $479^{\mathrm{b}}$ & - \\
\hline 9 & Luteolin hexoside & 28.0 & 255,349 & 447 & $285^{\mathrm{b}}$ & $241^{\mathrm{b}}, 223,213,175,151$ \\
\hline 10 & Patuletin hexoside & 28.6 & 254,365 & 493 & $331^{\mathrm{b}}, 316$ & $316^{\mathrm{b}}, 287$ \\
\hline 11 & 3,4-Di-O-caffeoylquinic acid & 31.9 & 294sh, 325 & 515 & $\begin{array}{c}\mathbf{3 5 3}^{\mathrm{b}}, 335,317,299 \\
203\end{array}$ & $191,179,173^{\mathrm{b}}$ \\
\hline 12 & 3,5-Di-O-caffeoylquinic acid & 32.5 & $294 \mathrm{sh}, 328$ & 515 & $353^{b}, 191$ & $191^{\mathrm{b}}, 179$ \\
\hline 13 & 1,5-Di-O-caffeoylquinic acid & 33.0 & $294 \mathrm{sh}, 328$ & 515 & $353^{b}, 191$ & $191^{\mathrm{b}}, 179$ \\
\hline 14 & 4,5-Di-O-caffeoylquinic acid & 36.2 & $294 \mathrm{sh}, 328$ & 515 & $\begin{array}{c}353^{\mathbf{b}}, 335,299,255 \\
203,173\end{array}$ & $191,179,173^{\mathrm{b}}$ \\
\hline 15 & $1,4,5$-Tri-O-caffeoylquinic acid & 40.4 & 294 sh, 325 & 677 & $515^{\mathrm{b}}, \mathbf{4 9 7}, 353,335$ & $353^{\mathrm{b}}, 335,191,179$ \\
\hline 16 & Tricaffeoylquinic acid derivative & 43.0 & 294sh, 327 & 793 & $\begin{array}{c}\mathbf{6 3 1} \mathbf{b}^{\mathbf{b}}, 613,515,498 \\
469\end{array}$ & $515,469^{\mathrm{b}}, 353$ \\
\hline 17 & Tricaffeoylquinic acid derivative & 45.2 & 294 sh, 329 & 793 & $\mathbf{6 3 1} 1^{\mathbf{b}}, 469,353$ & $469^{\mathrm{b}}, 353$ \\
\hline
\end{tabular}

${ }^{a}$ Identified by the reference standard.

${ }^{\mathrm{b}}$ Base peak. Bold-ions were subjected to $\mathrm{MS}^{3}$ fragmentation.

${ }^{\mathrm{c}}[\mathrm{M}+\mathrm{HCOO}]^{-}$.

tricaffeoylquinic acid substituted with an unidentified group. Due to the lack of suitable reference standards and literature data, the complete identification of these compounds needs isolation and full spectral characterization.

The analyzed extract of soil-grown roots only gave one peak with a UV-Vis spectrum demonstrating absorption maxima at $247 \mathrm{~nm}$, which is typical of ecdysones. The MS spectrum revealed its molecular mass to be $480 \mathrm{amu}$ based on $[\mathrm{M}+\mathrm{HCOO}]^{-}$ion at $m / z 525$ and $[\mathrm{M}-\mathrm{H}]^{-}$at $\mathrm{m} / z$ 479. A comparison of these spectral data with those obtained from the authentic standard allowed to confirm the identification of 20-hydroxyecdysone (compound 8) (Table 3).

The other group of compounds exhibits the UV-Vis spectra characteristic of flavonoids with two absorption maxima, first at $250-260 \mathrm{~nm}$ and second at $350-370 \mathrm{~nm}$. All compounds 5-7 and 9-10 were identified as flavonoid hexosides due to neutral losses of 162 mass units in their $\mathrm{MS}^{2}$ spectra. Flavonoid $\mathbf{5}$ was assigned as a quercetagetin hexoside, since the MS study of its deprotonated molecular ion $(\mathrm{m} / \mathrm{z}$ 479) provided a characteristic product ion at $m / z 317$ in the negative mode MS of quercetagetin aglycone [22]. Likewise, compound $\mathbf{1 0}$ was tentatively identified as patuletin hexoside by comparing its UV-Vis spectrum and fragmentation pattern of the aglycone moiety in $\mathrm{MS}^{3}$ spectrum with the literature [22]. Compounds 6 and 7 had identical MS profiles: fragmentation of deprotonated ion $[\mathrm{M}-\mathrm{H}]^{-}$at $\mathrm{m} / z 463$ yielded the base ion at $m / z 301$ in $\mathrm{MS}^{2}$ which corresponded to either of the two characteristic aglycones of $R$. carthamoides, quercetin, or 6-hydroxykaempferol [25-27]. According to the literature data, the MS spectra of quercetin and 6hydroxykaempferol reveal the presence of characteristic fragment ions at $\mathrm{m} / z 151$ and $\mathrm{m} / z 167$, respectively [22]. Thus, according to the observed $\mathrm{MS}^{3}$ fragmentation (Table 3), the aglycones of compounds $\mathbf{6}$ and $\mathbf{7}$ were assigned as quercetin. The $\mathrm{MS}^{2}$ spectrum of compound 9 revealed an ion of aglycone moiety at $m / z 285$, which could suggest the presence of luteolin or kaempferol. The comparison of the UV-Vis spectrum of 9 and the fragmentation pattern of its aglycone in $\mathrm{MS}^{3}$ spectrum with the literature $[22,28,29]$ indicated the presence of luteolin.

3.5. Quantitative HPLC-PDA Analysis. The contents of mono-, di-, and tricaffeoylquinic acids and their derivatives and flavonoid glycosides in HR-L an HR-D hairy roots selected from optimum medium (WPM) were determined by HPLC-PDA analysis and compared with the roots of 3year-old nontransformed plants of $R$. carthamoides grown in the soil (Table 4 and Figure 4). The growing interest of caffeoylquinic acids and their derivatives is based on their diverse biological activities which include anti-inflammatory, analgesic, antipyretic, and anticarcinogenic effects [30, 31]. Caffeoylquinic acids are free radical and metal scavengers and have been shown to modulate the gene expression of antioxidant enzymes [32]. Also, they have neuroprotective, neurotrophic [33], and hepatoprotective activity [34]. 
TABLE 4: Results of HPLC-PDA quantification of polyphenols and 20-hydroxyecdysone in hairy roots and in the roots of soil-grown plant extracts of R. carthamoides.

\begin{tabular}{|c|c|c|c|c|c|}
\hline Number & Compound & $t_{R}(\min )$ & $\begin{array}{c}\text { HR-L } \\
\mathrm{mgg}^{-1} \mathrm{DW}\end{array}$ & $\begin{array}{c}\text { HR-D } \\
\mathrm{mgg}^{-1} \mathrm{DW}\end{array}$ & $\begin{array}{c}\text { SR } \\
\mathrm{mg} \mathrm{g}^{-1} \mathrm{DW}\end{array}$ \\
\hline 1 & 3-O-Caffeoylquinic acid & 4.0 & $0.06(4.80)^{\mathrm{a}}$ & - & $0.70(0.34)^{\mathrm{b}}$ \\
\hline 2 & 5-O-Caffeoylquinic acid & 7.4 & $5.12(2.24)^{\mathrm{b}}$ & $1.96(2.92)^{\mathrm{a}}$ & $18.26(0.46)^{\mathrm{c}}$ \\
\hline 3 & 4-O-Caffeoylquinic acid & 8.1 & $0.12(5.03)^{\mathrm{b}}$ & $0.06(2.35)^{\mathrm{a}}$ & $0.42(0.95)^{\mathrm{c}}$ \\
\hline 4 & 1,3-Di-O-caffeoylquinic acid & 10.2 & $0.22(3.90)^{\mathrm{b}}$ & $0.12(2.68)^{\mathrm{a}}$ & $1.21(1.88)^{\mathrm{c}}$ \\
\hline 5 & Quercetagetin hexoside & 10.7 & $0.96(1.65)$ & - & - \\
\hline 6 & Quercetin hexoside & 11.4 & $0.93(1.71)$ & - & - \\
\hline 7 & Quercetin hexoside & 11.9 & $0.52(0.61)$ & - & - \\
\hline 8 & 20-Hydroxyecdysone & 12.0 & - & - & $5.60(1.36)$ \\
\hline 9 & Luteolin hexoside & 12.1 & $0.27(1.43)$ & - & - \\
\hline 10 & Patuletin hexoside & 12.2 & $0.25(1.24)$ & - & - \\
\hline 11 & 3,4-Di-O-caffeoylquinic acid & 13.1 & $0.22(0.95)^{b}$ & $0.15(3.67)^{\mathrm{a}}$ & $0.52(2.62)^{\mathrm{c}}$ \\
\hline 12 & 3,5-Di-O-caffeoylquinic acid & 13.4 & $3.08(3.32)^{\mathrm{b}}$ & $1.92(2.75)^{\mathrm{a}}$ & $8.47(0.51)^{\mathrm{c}}$ \\
\hline 13 & 1,5 -Di-O-caffeoylquinic acid & 13.9 & $0.28(3.28)^{b}$ & $0.12(3.01)^{\mathrm{a}}$ & $1.44(2.75)^{\mathrm{c}}$ \\
\hline 14 & 4,5-Di-O-caffeoylquinic acid & 14.1 & $1.97(3.39)^{\mathrm{c}}$ & $1.23(1.77)^{\mathrm{b}}$ & $1.04(2.05)^{\mathrm{a}}$ \\
\hline 15 & $1,4,5$-Tri- $O$-caffeoylquinic acid & 15.3 & $1.38(4.67)^{\mathrm{b}}$ & $1.08(2.86)^{\mathrm{a}}$ & - \\
\hline 16 & Tricaffeoylquinic acid derivative & 15.6 & $5.97(4.88)^{\mathrm{C}}$ & $4.34(2.09)^{\mathrm{b}}$ & $0.26(2.18)^{\mathrm{a}}$ \\
\hline 17 & Tricaffeoylquinic acid derivative & 16.4 & $0.66(0.24)^{\mathrm{b}}$ & $0.47(4.58)^{\mathrm{a}}$ & $2.88(1.38)^{\mathrm{c}}$ \\
\hline
\end{tabular}

Results are mean values of triplicate analyses calculated per DW of the plant material; the values in parentheses are relative standard deviations RSD (\%); different superscript letter within the rows indicates significant differences in the mean values at $P<0.01$ (one-way ANOVA by Tukey's test).

HR-L: hairy roots cultured in the WPM liquid medium, in the presence of light.

HR-D: hairy roots cultured in the WPM liquid medium, in darkness.

SR: roots of 3-year-old soil-grown plants.

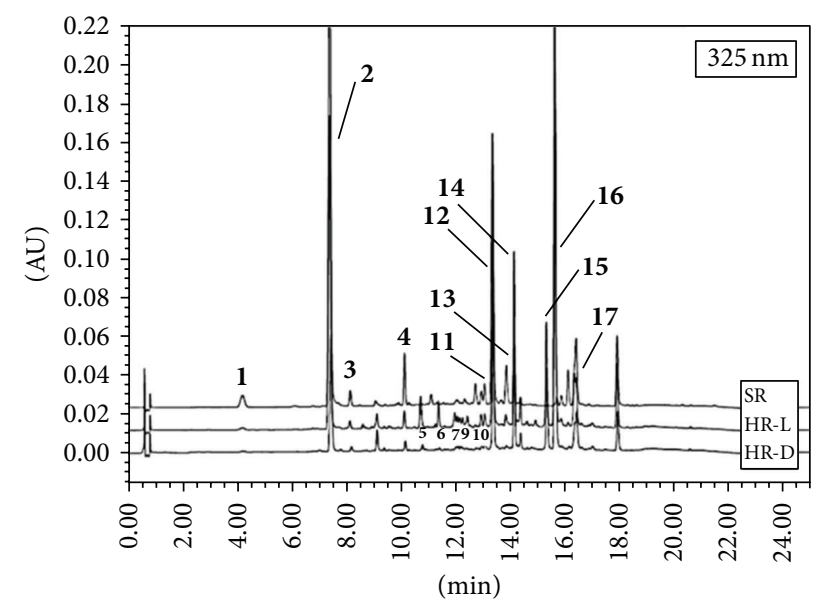

FIgURE 4: Representative HPLC-UV (325 nm) chromatograms of $R$. carthamoides root extracts. Sample and peak codes are given in Table 4.

The results indicate that the total concentration of caffeoylquinic acids and their derivatives (calculated as the sum of compounds 1-4 and 11-17) (Table 4) was about 2times higher in hairy roots cultured in photoperiod (HR-L) $\left(19.08 \mathrm{mg} \mathrm{g}^{-1} \mathrm{DW}\right)$ than that found in dark-grown hairy roots (HR-D) (11.45 $\left.\mathrm{mg} \mathrm{g}^{-1} \mathrm{DW}\right)$ (Table 4). The mean individual caffeic acid derivative content followed a similar pattern. It suggests a regulation response to light of the phenylpropanoid biosynthetic pathway. The positive effect of light on the biosynthesis of caffeic acid derivatives has been observed in transformed roots of some other plant species, such as Echinacea purpurea [35] and Cichorium intybus [36].

5-O-caffeoylquinic acid (chlorogenic acid, compound 2) (Table 4, Figure 4) was the main constituent of the monocaffeoylquinic acid derivatives detected in the transformed roots of $R$. carthamoides. Its content ranged from $1.96 \mathrm{mg} \mathrm{g}^{-1}$ DW to $5.12 \mathrm{mg} \mathrm{g}^{-1} \mathrm{DW}$ and was higher in HR-L root culture (Table 4). The amounts were much higher than chlorogenic acid level in transformed roots of Echinacea purpurea [35, 37], Fagopyrum tataricum [38], or Polygonum multiflorum [39]. In transformed roots of $R$. carthamoides the chlorogenic acid was further esterified with caffeic acid to produce the 3,5-di-O-caffeoylquinic acid (compound 12) (Table 4). The amount of the compound was $3.08 \mathrm{mg} \mathrm{g}^{-1} \mathrm{DW}$ in HR-L and $1.92 \mathrm{mg} \mathrm{g}^{-1} \mathrm{DW}$ in HR-D (Table 4). Additionally, in extracts of HR-L and HR-D four other dicaffeoylquinic acids were found but at considerably lower amounts compared with 3,5-O-dicaffeoylquinic acid (Table 4). In both types of $R$. carthamoides hairy root culture, the predominant fraction was tricaffeoylquinic acid derivatives $\left(8.01 \mathrm{mg} \mathrm{g}^{-1} \mathrm{DW}\right.$ and $5.89 \mathrm{mg} \mathrm{g}^{-1}$ DW in HR-L and HR-D hairy roots, resp.) with compound 16 (substituted tricaffeoylquinic acid) being the most abundant component. This compound represented up to $75 \%$ of the sum of the tricaffeoylquinic acids detected in transformed roots (Table 4). The tricaffeoylquinic acids and their derivatives are less common in plants than mono-, and dicaffeoyl ones [34]. This type of compounds was earlier 
identified in other species of family Asteraceae, such as Arnica montana [21] and Erigeron breviscapus [20]. To date there have been no reports on tricaffeoylquinic acid production in $R$. carthamoides.

Considerable differences in qualitative and quantitative profiles of phytochemicals between transformed roots and normal roots of soil-grown plants of $R$. carthamoides (SR) were observed. The production of caffeoylquinic acids and their derivatives was 2-3-times higher in SR roots than in transformed roots. The most prominent component of SR roots was chlorogenic acid (18.26 $\left.\mathrm{mgg}^{-1} \mathrm{DW}\right)$ (Table 4). The SR roots accumulated 17-23 times less of compound 16 (tricaffeoylqunic acid derivative) than transformed roots, which was dominant component in the latter. Moreover, 1,4,5-tri-O-caffeoylquinic acid (compound 15) (Table 4) was identified only in the hairy root cultures. The differences between transformed roots and nontransformed roots of $R$. carthamoides were also observed in respect to other groups of secondary metabolites. Only hairy roots were able to produce the flavonoid glycosides (quercetagetin, quercetin, luteolin, and patuletin hexosides) when they were cultured in the light conditions. The total flavonoid content in this sample was $2.93 \mathrm{mg} \mathrm{g}^{-1} \mathrm{DW}$ (Table 4). A comparative study of the ecdysteroids of transformed and normal roots of $R$. carthamoides showed that 20-hydroxyecdysone (compound 8) was only produced in the latter, reaching a level of $5.6 \mathrm{mg}$ $\mathrm{g}^{-1}$ DW (Table 4).

The results of the present study showed that the transformation by A. rhizogenes strain A4 led to important modification of the metabolic pathways. Differences in the chemical profiles of transformed and normal roots have been also reported in other plant species $[40,41]$ which indicate that the insertion of Ri T-DNA interferes with the biosynthesis of the secondary metabolites. However, the differences observed between transformed and normal roots of $R$. carthamoides with regard to the qualitative and quantitative spectra of secondary metabolites could be also caused by differences in the developmental stage of roots or by environmental conditions (in vitro or in vivo).

\section{Conclusions}

The present study demonstrates that hairy roots of $R$. carthamoides are easily grown in liquid WPM medium. They produce a substantial biomass of approximately $90 \mathrm{~g} \mathrm{~L}^{-1}$ of fresh weight in $80 \mathrm{~mL}$ medium after a short cultivation period of 35 days. The establishment of hairy root culture with highly increased levels of tricaffeoylquinic acids and their derivatives observed in the present study indicates that the hairy roots can be used as potential sources of these secondary metabolites instead of the normal roots of soil-grown plants. This is especially important because tricaffeoylquinic acids have been shown to possess antimutagenic, antihyperglycemic, strong antioxidant, and radical scavenging effects. However, it has been found that the tricaffeoylquinic acids have more biological activity than mono- and dicaffeoylquinic acid derivatives [42-44]. The antioxidant activity of hairy roots is currently under investigation.

\section{Conflict of Interests}

The authors declare that there is no conflict of interests regarding the publication of this paper.

\section{Acknowledgment}

This work was financially supported by Medical University of Łódź (Grants nos. 503/3-012-01/503-01 and 503/3-02201/503-01).

\section{References}

[1] L. Kokoska and D. Janovska, "Chemistry and pharmacology of Rhaponticum carthamoides: a review," Phytochemistry, vol. 70, no. 7, pp. 842-855, 2009.

[2] Y. Kim, B. E. Wyslouzil, and P. J. Weathers, "Secondary metabolism of hairy root cultures in bioreactors," In Vitro Cellular and Developmental Biology-Plant, vol. 38, no. 1, pp. 1-10, 2002.

[3] S. Chandra and R. Chandra, "Engineering secondary metabolite production in hairy roots," Phytochemistry Reviews, vol. 10, no. 3, pp. 371-395, 2011.

[4] I. V. Orlova, N. S. Zakharchenko, E. G. Semenyuk, A. M. Nosov, V. V. Volodin, and Y. I. Bur'yanov, "The initiation of transformed root culture from Rhaponticum carthamoides," Russian Journal of Plant Physiology, vol. 45, no. 3, pp. 339-341, 1998.

[5] T. Murashige and F. Skoog, "A revised medium for rapid growth and bioassays with tobacco tissue cultures," Physiologia Plantarum, vol. 15, no. 3, pp. 473-497, 1962.

[6] G. Vervliet, M. Holsters, H. Teuchy, M. Van Montagu, and J. Schell, "Characterization of different plaque forming and defective temperate phages in Agrobacterium strains," Journal of General Virology, vol. 26, no. 1, pp. 33-48, 1975.

[7] O. L. Gamborg, R. A. Miller, and K. Ojima, "Nutrient requirements of suspension cultures of soybean root cells," Experimental Cell Research, vol. 50, no. 1, pp. 151-158, 1968.

[8] R. U. Schenk and A. C. Hildebrandt, "Medium and techniques for induction and growth of monocotyledonous and dicotyledonous plant cell cultures," Canadian Journal of Botany, vol. 50, no. 1, pp. 199-204, 1972.

[9] G. B. Lloyd and B. H. McCown, "Commercially-feasible micropropagation of mountain lamel Kalmia latifolia by use of shoottip culture," in Proceedings of the International Plant Propagator's Society, vol. 30, pp. 421-427, 1980.

[10] P. C. Verma, L. U. Rahman, A. S. Negi, D. C. Jain, S. P. S. Khanuja, and S. Banerjee, "Agrobacterium rhizogenes-mediated transformation of Picrorhiza kurroa Royle ex Benth.: establishment and selection of superior hairy root clone," Plant Biotechnology Reports, vol. 1, no. 3, pp. 169-174, 2007.

[11] R. P. Chandran and V. P. Potty, "Different inducer molecules and strains of Agrobacterium rhizogenes on enhancing transformation frequency in host plants," Biotechnology, vol. 10, no. 2, pp. 203-208, 2011.

[12] S. B. Gelvin, "Agrobacterium and plant genes involved in TDNA transfer and integration," Annual Review of Plant Biology, vol. 51, pp. 223-256, 2000.

[13] W. W. Bhat, S. K. Lattoo, S. Rana et al., "Efficient plant regeneration via direct organogenesis and Agrobacterium tumefaciens-mediated genetic transformation of Picrorhiza kurroa: an endangered medicinal herb of the alpine Himalayas," In Vitro 
Cellular and Developmental Biology_Plant, vol. 48, no. 3, pp. 295-303, 2012.

[14] P. A. G. Santos, A. C. Figueiredo, M. M. Oliveira et al., "Growth and essential oil composition of hairy root cultures of Levisticum officinale W.D.J. Koch (lovage)," Plant Science, vol. 168, no. 4, pp. 1089-1096, 2005.

[15] A. Merkli, P. Christen, and I. Kapetanidis, "Production of diosgenin by hairy root cultures of Trigonella foenum-graecum L.," Plant Cell Reports, vol. 16, no. 9, pp. 632-636, 1997.

[16] I. Weremczuk-Jezyna, I. Grzegorczyk-Karolak, B. Frydrych, A. Królicka, and H. Wysokińska, "Hairy roots of Dracocephalum moldavica: rosmarinic acid content and antioxidant potential," Acta Physiologiae Plantarum, vol. 35, no. 7, pp. 2095-2103, 2013.

[17] M. Kino-oka, H. Nagatome, and M. Taya, "Characterization and application of plant hairy roots endowed with photosynthetic functions," Advances in Biochemical Engineering/Biotechnology, vol. 72, pp. 183-218, 2001.

[18] A. Jacob and N. Malpathak, "Green hairy root cultures of Solanum khasianum Clarke-a new route to in vitro solasodine production," Current Science, vol. 87, no. 10, pp. 1442-1447, 2004.

[19] M. N. Clifford, L. J. Kelly, S. Knight, and N. Kuhnert, "Hierarchical scheme for LC-MS ${ }^{n}$ identification of chlorogenic acids," Journal of Agricultural and Food Chemistry, vol. 51, no. 10, pp. 2900-2911, 2003.

[20] S.-G. Liao, L.-J. Zhang, C.-B. Li et al., "Rapid screening and identification of caffeic acid and its esters in Erigeron breviscapus by ultra-performance liquid chromatography/tandem mass spectrometry," Rapid Communications in Mass Spectrometry, vol. 24, no. 17, pp. 2533-2541, 2010.

[21] L.-Z. Lin and J. M. Harnly, "Identification of hydroxycinnamoylquinic acids of Arnica flowers and burdock roots using a standardized LC-DAD-ESI/MS profiling method," Journal of Agricultural and Food Chemistry, vol. 56, no. 21, pp. 10105-10114, 2008.

[22] I. Parejo, O. Jáuregui, F. Viladomat, J. Bastida, and C. Codina, "Characterization of acylated flavonoid-O-glycosides and methoxylated flavonoids from Tagetes maxima by liquid chromatography coupled to electrospray ionization tandem mass spectrometry," Rapid Communications in Mass Spectrometry, vol. 18, no. 23, pp. 2801-2810, 2004.

[23] M. N. Clifford, T. Williams, and D. Bridson, "Chlorogenic acids and caffeine as possible taxonomic criteria in Coffea and Psilanthus," Phytochemistry, vol. 28, no. 3, pp. 829-838, 1989.

[24] M. N. Clifford, S. Knight, and N. Kuhnert, "Discriminating between the six isomers of dicaffeoylquinic acid by LC-MS ${ }^{n}$," Journal of Agricultural and Food Chemistry, vol. 53, no. 10, pp. 3821-3832, 2005.

[25] E. Varga, G. Sarik, K. Szendrei, and I. Pelczer, "Flavonoids from Leuzea carthamoides DC," Herba Hungarica, vol. 29, no. 1-2, pp. 51-55, 1990.

[26] M. Sharaf, A. Skiba, Z. Weglarz, and M. A. El-Ansari, "Two flavonol 5-O-glycosides from the roots of Leuzea carthamoides," Fitoterapia, vol. 72, no. 8, pp. 940-942, 2001.

[27] G. Miliauskas, T. A. van Beek, P. de Waard, R. P. Venskutonis, and E. J. R. Sudhölter, "Identification of radical scavenging compounds in Rhaponticum carthamoides by means of LCDAD-SPE-NMR," Journal of Natural Products, vol. 68, no. 2, pp. 168-172, 2005.

[28] D. Tsimogiannis, M. Samiotaki, G. Panayotou, and V. Oreopoulou, "Characterization of flavonoid subgroups and hydroxy substitution by HPLC-MS/MS," Molecules, vol. 12, no. 3, pp. 593-606, 2007.
[29] S. Granica, K. Krupa, A. Kłębowska, and A. K. Kiss, "Development and validation of HPLC-DAD-CAD-MS ${ }^{3}$ method for qualitative and quantitative standardization of polyphenols in Agrimoniae eupatoriae herba (Ph. Eur)," Journal of Pharmaceutical and Biomedical Analysis, vol. 86, pp. 112-122, 2013.

[30] H. Shibata, Y. Sakamoto, M. Oka, and Y. Kono, "Natural antioxidant, chlorogenic acid, protects against DNA breakage caused by monochloramine," Bioscience, Biotechnology and Biochemistry, vol. 63, no. 7, pp. 1295-1297, 1999.

[31] M. D. dos Santos, M. C. Almeida, N. P. Lopes, and G. E. P. de Souza, "Evaluation of the anti-inflammatory, analgesic and antipyretic activities of the natural polyphenol chlorogenic acid," Biological and Pharmaceutical Bulletin, vol. 29, no. 11, pp. 2236-2240, 2006.

[32] A. Gugliucci and D. H. M. Bastos, "Chlorogenic acid protects paraoxonase 1 activity in high density lipoprotein from inactivation caused by physiological concentrations of hypochlorite," Fitoterapia, vol. 80, no. 2, pp. 138-142, 2009.

[33] W. Shen, R. Qi, J. Zhang et al., "Chlorogenic acid inhibits LPS-induced microglial activation and improves survival of dopaminergic neurons," Brain Research Bulletin, vol. 88, no. 5, pp. 487-494, 2012.

[34] H.-J. Park, "Chemistry and pharmacological action of caffeoylquinic acid derivatives and pharmaceutical utilization of chwinamul (Korean Mountainous Vegetable)," Archives of Pharmacal Research, vol. 33, no. 11, pp. 1703-1720, 2010.

[35] B. H. Abbasi, C.-L. Tian, S. J. Murch, P. K. Saxena, and C.-Z. Liu, "Light-enhanced caffeic acid derivatives biosynthesis in hairy root cultures of Echinacea purpurea," Plant Cell Reports, vol. 26, no. 8, pp. 1367-1372, 2007.

[36] J. Malarz, A. Stojakowska, and W. Kisiel, "Long-term cultured hairy roots of chicory-a rich source of hydroxycinnamates and 8-deoxylactucin glucoside," Applied Biochemistry and Biotechnology, vol. 171, no. 7, pp. 1589-1601, 2013.

[37] C.-Z. Liu, B. H. Abbasi, M. Gao, S. J. Murch, and P. K. Saxena, "Caffeic acid derivatives production by hairy root cultures of Echinacea purpurea," Journal of Agricultural and Food Chemistry, vol. 54, no. 22, pp. 8456-8460, 2006.

[38] Y. K. Kim, X. Li, H. Xu et al., "Production of phenolic compounds in hairy root culture of tartary buckwheat (Fagopyrum tataricum Gaertn)," Journal of Crop Science and Biotechnology, vol. 12, no. 1, pp. 53-58, 2009.

[39] M. Thiruvengadam, N. Praveen, E.-H. Kim, S.-H. Kim, and I.-M. Chung, "Production of anthraquinones, phenolic compounds and biological activities from hairy root cultures of Polygonum multiflorum Thunb.," Protoplasma, vol. 251, no. 3, pp. 555-566, 2014.

[40] M. Sidwa-Gorycka, A. Krolicka, A. Orlita et al., "Genetic transformation of Ruta graveolens L. by Agrobacterium rhizogenes: hairy root cultures a promising approach for production of coumarins and furanocoumarins," Plant Cell, Tissue and Organ Culture, vol. 97, no. 1, pp. 59-69, 2009.

[41] Y. Zhou, M. Hirotani, T. Yoshikawa, and T. Furuya, "Flavonoids and phenylethanoids from hairy root cultures of Scutellaria baicalensis," Phytochemistry, vol. 44, no. 1, pp. 83-87, 1997.

[42] M. S. Islam, M. Yoshimoto, and O. Yamakawa, "Distribution and physiological functions of caffeoylquinic acid derivatives in leaves of sweetpotato genotypes," Journal of Food Science, vol. 68, no. 1, pp. 111-116, 2003.

[43] S. M. Kim, J.-S. Jeon, S. W. Kang, Y.-J. Jung, L. N. Ly, and B.-H. $\mathrm{Um}$, "Content of antioxidative caffeoylquinic acid derivatives in 
field-grown Ligularia fischeri (Ledeb.) Turcz and responses to sunlight," Journal of Agricultural and Food Chemistry, vol. 60, no. 22, pp. 5597-5603, 2012.

[44] T. Matsui, S. Ebuchi, T. Fujise et al., "Strong antihyperglycemic effects of water-soluble fraction of Brazilian propolis and its bioactive constituent, 3,4,5-tri-O-caffeoylquinic acid," Biological and Pharmaceutical Bulletin, vol. 27, no. 11, pp. 1797-1803, 2004. 

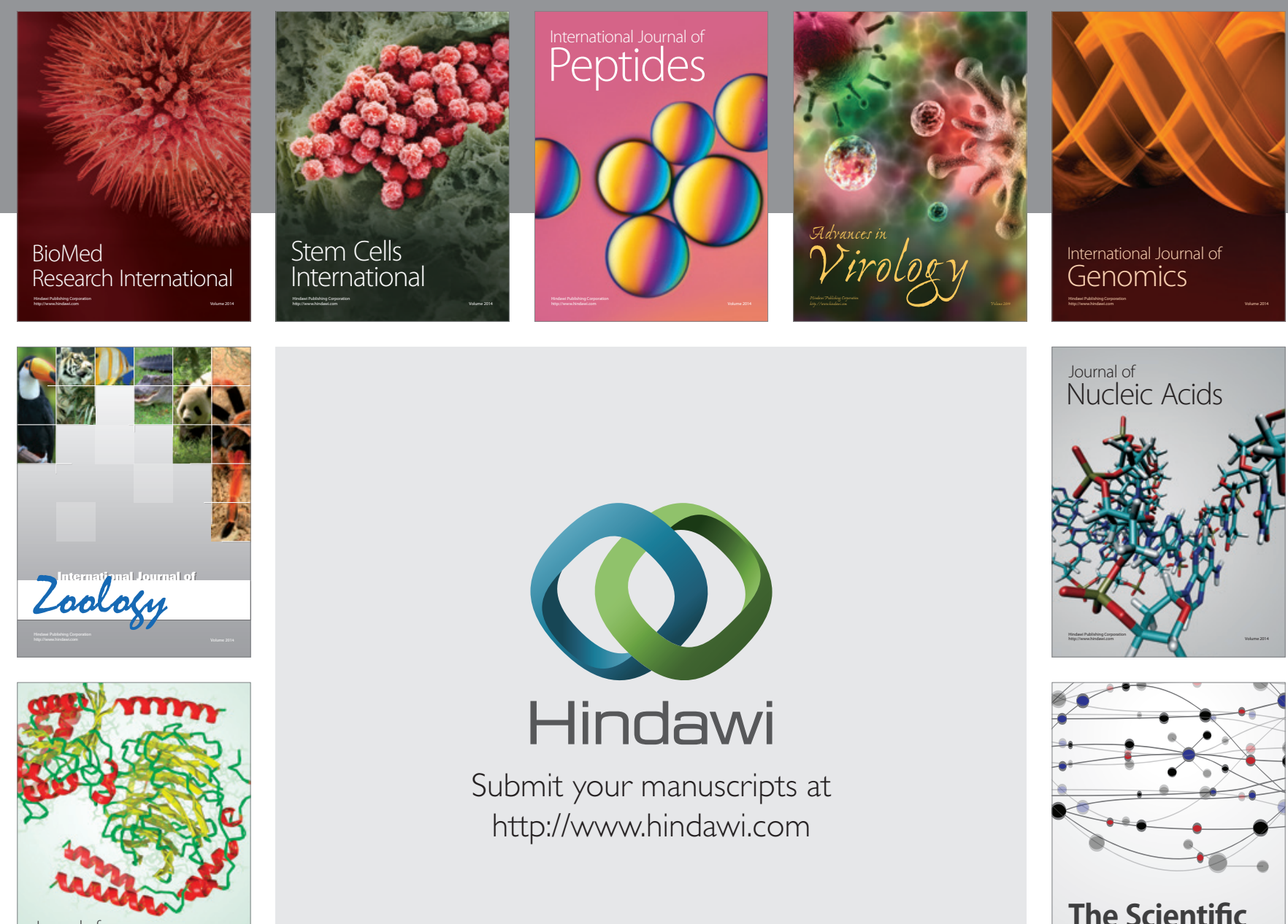

Submit your manuscripts at

http://www.hindawi.com

Journal of
Signal Transduction
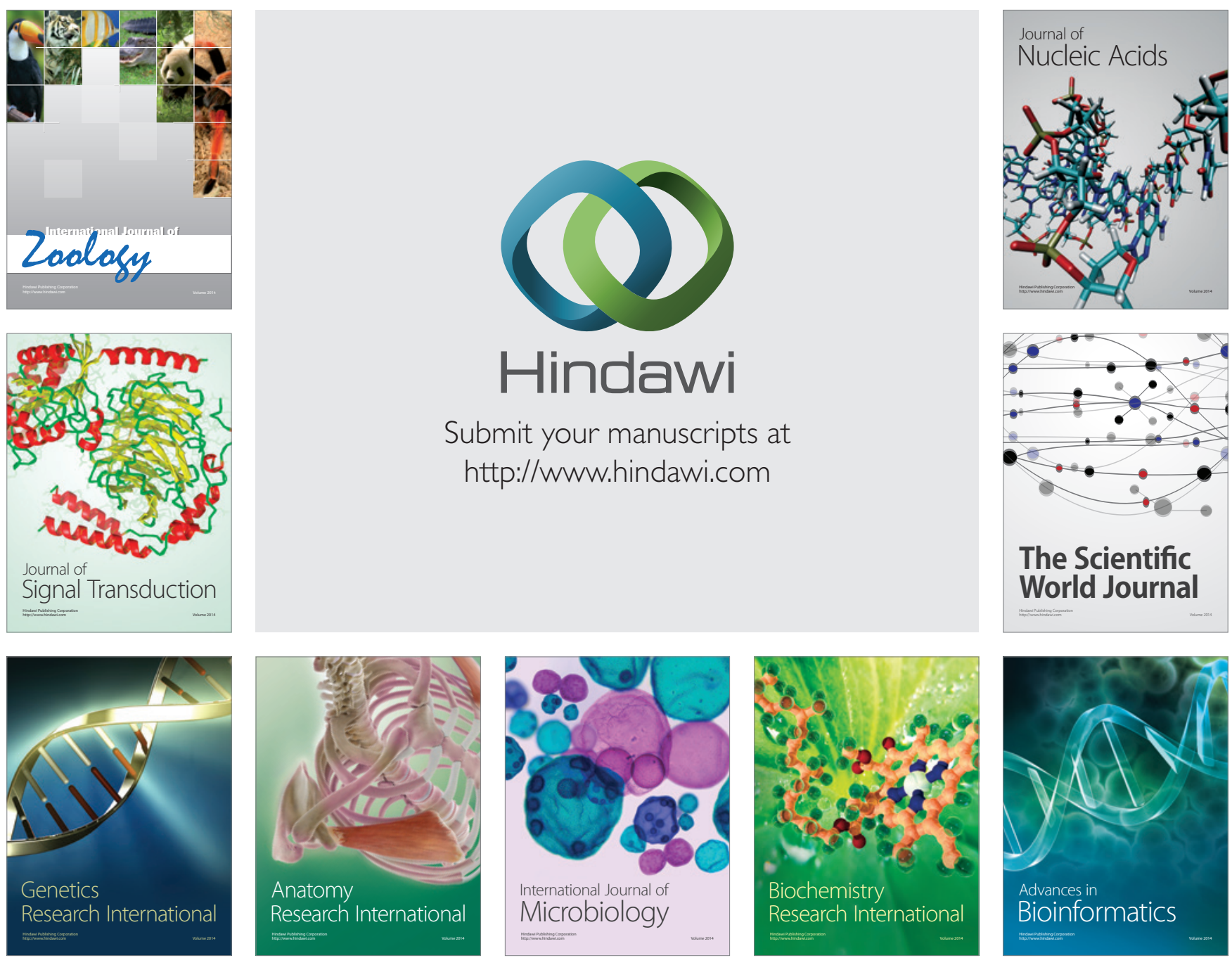

The Scientific World Journal
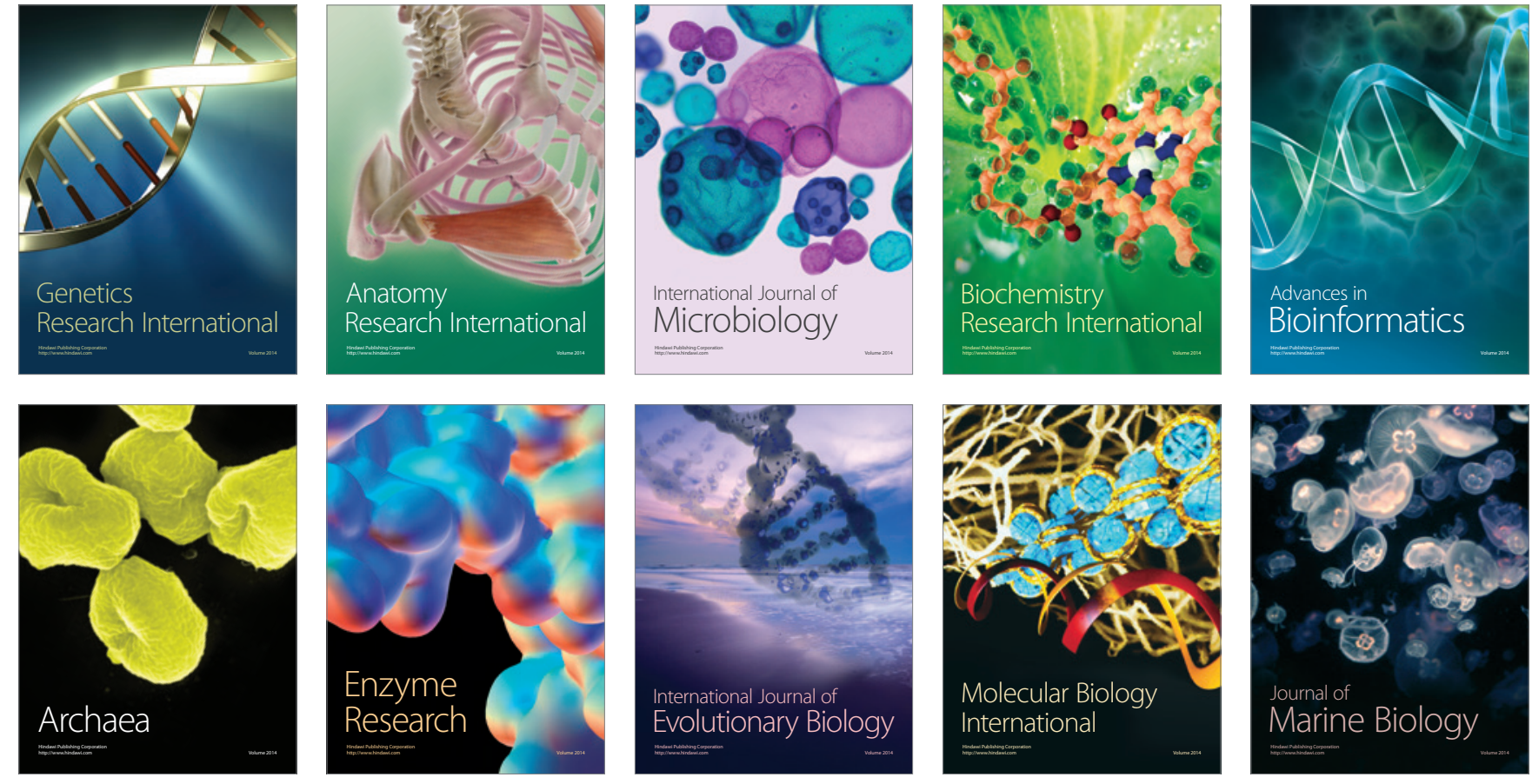